\title{
Cardiorespiratory Effects of Derotational Casting during Anesthesia for Children with Early Onset Scoliosis
}

\author{
Robin D. Jensen, Andrew F. Stasic, Shyam Kishan, Eric Scott, Deann M. Martin, Stephen F. Dierdorf
}

Riley Hospital for Children at IU Health, Indiana University School of Medicine, Indianapolis, USA.

Email: sstev47@aol.com

Received December $8^{\text {th }}$, 2014; revised January $8^{\text {th }}$, 2014; accepted January $18^{\text {th }}, 2014$

Copyright (c) 2014 Robin D. Jensen et al. This is an open access article distributed under the Creative Commons Attribution License, which permits unrestricted use, distribution, and reproduction in any medium, provided the original work is properly cited. In accordance of the Creative Commons Attribution License all Copyrights (c) 2014 are reserved for SCIRP and the owner of the intellectual property Robin D. Jensen et al. All Copyright (c) 2014 are guarded by law and by SCIRP as a guardian.

\begin{abstract}
Study Design: A prospective, observational case series of eighteen children with early onset scoliosis undergo spine manipulation and casting. Objective: Determine if respiratory system compliance decreases during casting warrants tracheal intubation in all Derotational casting procedures. Background: Children with early onset scoliosis with a Cobb angle greater than 25 degrees will have significant progression of their scoliosis. Surgical techniques cannot result in spine fusion as growth retardation will ensue. Serial thoracolumbar casting may correct the scoliosis or delay the need for surgery. The cast, however, is highly restrictive until the cast is appropriately cut. Does respiratory system compliance decrease a significant degree to require tracheal intubation in all Derotational casting procedures? Methods: Eighteen children (mean age: 4.5 years, mean weight: 16.9 kg) undergoing initial scoliosis casting were enrolled. Anesthesia was induced with sevoflurane in oxygen, an intravenous catheter was inserted, intravenous propofol administered and tracheal intubation performed. Baseline measurements of heart rate, blood pressure, $\mathrm{SpO}_{2}$, peak inspiratory pressure (PIP), and pulmonary compliance were made before casting, immediately after casting, and after cast cut-out. Results: PIP increased from $15.8 \mathrm{~cm} \mathrm{H}_{2} \mathrm{O}$ to 42.6 after cast application and decreased to 20.2 after cast cut-out. Compliance decreased from $1.08 \mathrm{ml} / \mathrm{cm} \mathrm{H}_{2} \mathrm{O} / \mathrm{kg}$ to 0.21 after cast application and increased to 0.61 after cast cut-out. There were no clinically significant changes in heart rate, blood pressure, or $\mathrm{SpO}_{2}$. Conclusion: The thoracolumbar cast applied for scoliosis treatment causes severe restriction of chest wall movement and subsequent deterioration of pulmonary function. The time of severe restriction of chest wall motion is short and is relieved once cast cut-outs are performed. The marked increase in PIP and decrease in compliance that occurs during the casting process necessitates tracheal intubation.
\end{abstract}

\section{KEYWORDS}

\section{Derotational Casting; Early Onset Scoliosis; Respiratory Compliance}

\section{Introduction}

Untreated scoliosis can lead to significant cardiorespiratory dysfunction. Scoliotic changes in chest wall architecture over stretch chest wall muscles on the convex side of the thoracic spine curve and cause muscle contracture on the concave side of the curve. The thoracic cage asymmetry causes aberrations in muscle lengthtension relationships resulting in increased work of breathing [1,2]. Abnormal thoracic cage growth restricts pulmonary alveolar development thereby causing pulmonary hypoplasia and/or atelectasis. Scoliosis produces a restrictive lung disease pattern, the severity of which may be determined by the age of onset relative to the time of alveolar development [3,4]. A decreased space available for the lung especially between the ages of 5 to 8 years inhibits the alveolar hyperplasia phase of lung development. Continued chest wall deformity will then impact the alveolar hypertrophy that normally doubles the lung volume between 10 and 18 years of age. Although the restrictive effects on the lung are initially secondary to poor chest wall mechanics, long standing hypo-inflation of the lung and retention of secretions can also lead to intrinsic obstructive pulmonary disease. De- 
creased thoracic capacity may decrease cardiac performance and diminish exercise capacity. Mitral valve prolapse occurs in 25 per cent of patients with scoliosis [5]. Mitral valve prolapse may be a manifestation of a collagen defect that could also be responsible for the scoliosis.

There is no known cause for 85 percent of the cases of scoliosis (idiopathic). The defect in idiopathic scoliosis is a postulated discordance between the anterior and posterior vertebral elements eventually resulting in displacement of the vertebral bodies into fairly consistent curve patterns [6]. Idiopathic scoliosis is classified by age of onset as infantile, juvenile, or adolescent. Infantile scoliosis and juvenile scoliosis are more commonly classified as one group termed early onset scoliosis (EOS). Young children with a Cobb angle of greater than 25 degrees will have significant progression of their scoliosis before skeletal maturity is achieved [7]. If uncorrected, patients with early onset scoliosis are more likely to develop respiratory failure, cor pulmonale, and premature death than patients with adolescent scoliosis [8,9]. Early intervention may prevent thoracic cage deformation and improve pulmonary function. Surgical correction or palliation for scoliosis is associated with excessive blood loss, spinal cord ischemia, pulmonary morbidity, and protracted recovery. Surgical intervention in young children with scoliosis may have adverse effects on thoracic growth, has a greater risk of perioperative complications, and is more likely to produce adverse psychological effects than surgical correction in adolescents [10,11]. Studies of the long-term effects of surgery on postoperative respiratory function in young children with scoliosis have yielded conflicting results [12].

Mehta and others popularized non-operative treatment of scoliosis with the successive application of derotational casts in children with early onset scoliosis with the hope of early correction without invasive surgery $[13,14]$. This process requires the application of successive thoracolumbar casts that are molded after application for the child's specific deformity. The casts are applied with the patient under general anesthesia on a casting frame. The cast is extremely restrictive to chest wall excursion until the appropriate windows are cutout. The restrictive nature of the cast is associated with high peak inspiratory pressures during the casting process [15].

Any growing child up to 7 to 8 years of age (the development period of alveolar hyperplasia) with curves greater than 25 degrees is a candidate for this non-operative approach. The goal is to correct the spinal and chest wall deformity and allow pulmonary development. In some children the deformity is fully corrected, in others the curves stabilize without progression, and in many, surgical treatment is effectively postponed.

This prospective study was performed in children presenting for initial casting. The anesthetic technique was controlled. No patients received muscle relaxants and remained at a constant depth of anesthesia.

\section{Methods}

After Institutional Review Board (IRB) approval and written parental consent, patients with early onset scoliosis presenting for their first cast were enrolled. Twenty patients between the ages of 1 and 8 years (mean age 5.1 years) were enrolled in the study. Two patients were dropped from consideration because of incomplete data acquisition. Eighteen patients completed the study (mean age 4.5 years, $16.9 \mathrm{~kg}$ ) (mean Cobb angle 46 degrees, range 30 - 62 degrees). A standard anesthetic technique was used. Patients received oral midazolam $(0.5 \mathrm{mg} / \mathrm{kg})$ 20 to 25 minutes prior to induction of anesthesia. Anesthesia was induced with sevoflurane in oxygen by face mask with a Drager Apollo anesthesia machine. An intravenous catheter was inserted after the induction of anesthesia. Propofol (3 mg/kg i.v.) was administered to facilitate tracheal intubation with an appropriately sized cuffed tracheal tube. Muscle relaxants were not administered. After tracheal intubation, anesthesia was maintained with sevoflurane in oxygen. Mechanical ventilation was achieved with a tidal volume of $8 \mathrm{ml} / \mathrm{kg}$ in volume control mode. The I:E ratio was set at $1: 2$ and the respiratory rate was set to maintain an end-tidal carbon dioxide between 32 and $42 \mathrm{~mm} \mathrm{Hg}$. The entire casting procedure from the time of induction to emergence averaged 68 minutes. The time from induction to the first set of measurements is approximately 10 minutes and the time from induction to completion of casting is $30 \mathrm{mi}-$ nutes. The time in the restrictive cast is approximately 10 minutes and another 10 minutes is required for completion of cast window cutout. The first measurements were made when a constant level of anesthesia was obtained as defined by a stable ratio of the inspired concentration of sevoflurane to the expired concentration of sevoflurane.

Respiratory function parameters were measured with a Philips M1014A Spirometry Module connected to a Philips Intellivue monitor. Respiratory parameters measured were arterial oxygen saturation $\left(\mathrm{SpO}_{2}\right)$, end-tidal carbon dioxide $\left(\mathrm{ETCO}_{2}\right)$, tidal volume, respiratory rate, peak inspiratory pressure (PIP), and dynamic compliance. The module measures dynamic compliance, which is the ratio of change in volume to the change in pressure during inspiration. Dynamic compliance is calculated using the least squares fitting method of the flow, volume, and raw pressure waveform [16-18]. Blood pressure was measured with an automated NIBP device (Philips Intellivue MP70). Measurements were obtained at three different periods: 1) baseline, after induction of anesthesia and tracheal intubation, 2) after application of the body cast on the casting frame, and 3) after cast window cutout. Prior to all measurements and without any manipulation 
of the patient, 60 to 90 seconds of equilibration was allowed. Ten to 15 breaths of equilibration were done prior to measurement of respiratory parameters.

Repeated measures ANOVA was used for statistical comparison of values after induction of anesthesia (baseline), immediately after cast application, and following cast window cutout.

\section{Results}

The baseline measurements of compliance during anesthesia and controlled ventilation were similar to those reported in another study of young children [19]. Casting produced a precipitous increase in PIP ( $p<0.0001)$ and decrease in compliance $(\mathrm{p}<0.0001)$ (Table 1). PIP increased by 170 per cent and compliance decreased to 19 per cent of baseline. After cast window cutouts were performed, PIP increased to 56 per cent of baseline. The increase in compliance after cutout was statistically greater $(\mathrm{p}<0.01)$ than compliance after cast application, but was statistically less than baseline compliance $(\mathrm{p}<$ 0.01). PIP decreased significantly after cast cutout but was statistically higher than baseline PIP. Tidal volume $\left(\mathrm{V}_{\mathrm{T}}\right)$ decreased from $8.8 \mathrm{ml} / \mathrm{kg}$ at baseline to $7.1 \mathrm{ml} / \mathrm{kg}(\mathrm{p}$ $<0.004$ ) after cast application, but increased to $8.5 \mathrm{ml} / \mathrm{kg}$ after cast cutout ( $\mathrm{p}<0.002$ compared to $\mathrm{V}_{\mathrm{T}}$ after casting). Five patients had no change in $\mathrm{V}_{\mathrm{T}}$ from baseline to cast application and 13 had a decrease in $\mathrm{V}_{\mathrm{T}}$. There was, however, no statistically significant difference in compliance changes between patients with no change in tidal volume and those patients with a change in tidal volume.

There was no change in end-tidal sevoflurane concentration between baseline and cast application. There was, however, a statistically significant decrease in end-tidal sevoflurane concentration from baseline to cast cutout ( $\mathrm{p}$ $<0.007$ ).

Mean arterial blood pressure (MABP) increased from
$52.4 \mathrm{~mm} \mathrm{Hg}$ at baseline to 65.2 after cast application $(\mathrm{p}<$ 0.05). After cast cutout, MABP decreased to $56.8 \mathrm{~mm} \mathrm{Hg}$. Heart rate did not change significantly with cast application, but decreased from 119 beats per minute at baseline to 106 beats per minute after cast cutout $(\mathrm{p}<0.05)$.

\section{Discussion}

If untreated, early onset scoliosis will progress and may ultimately result in thoracic insufficiency, cor pulmonale, and premature death. The treatment of EOS, however, is controversial $[20,21]$. Any technique that fuses the spine at an early age will limit thoracic and pulmonary maturation [22]. Surgical techniques such as growing rods (single or dual), VEPTR, or hybrid distraction systems do not fuse the spine, but require repeated invasive surgical adjustments. The derotational casting process requires repeated cast applications, but the technique is non-invasive and is associated with minimal risk. Derotational casting may eliminate the need for surgery or delay the need for surgery until the spine has achieved maximal growth. Irrespective of the type of treatment, preservation or improvement in respiratory mechanics is a primary goal of scoliosis treatment. Cast therapy for EOS may become more common if surgical techniques prove to have poor outcomes and a high incidence of perioperative complications.

This study objectively evaluated the effects of casting on respiratory mechanics. Respiratory system compliance decreased markedly and PIP increased significantly during the time that the cast was restrictive to chest wall motion. Despite these changes, there were no adverse effects such as barotrauma, hypoxemia, hypercarbia, or hypotension. Although anesthesia for many orthopedic casting procedures is administered through a supraglottic airway or by face mask with a pharyngeal airway, the application of the restrictive body cast requires

Table 1. Cardiorespiratory change during scoliosis casting.

\begin{tabular}{cccc}
\hline Parameter & Baseline & After Cast & After Cast Cutout \\
\hline PIP $\left(\mathrm{cm} \mathrm{H}_{2} \mathrm{O}\right)$ & $15.8(3.2)$ & $42.6(7.9)^{*}$ & $20.2(3.2)^{* *}$ \\
$\mathrm{C}_{\mathrm{dyn}}$ & $1.08(0.24)$ & $0.21(0.08)^{*}$ & $0.61(0.15)^{* *}$ \\
$\mathrm{~V}_{\mathrm{T}}$ & $8.8(0.8)$ & $7.1(1.7)^{*}$ & $8.5(0.8)^{\#}$ \\
Heart rate (bpm) & $119(17)$ & $113(21)$ & $106(20)^{* *}$ \\
MABP (mmHg) & $52.4(8.7)$ & $65.2(13)^{*}$ & $56.8(8.7)^{*}$ \\
$\mathrm{~S}_{\mathrm{p}} \mathrm{O}_{2}(\%)$ & $99.7(.58)$ & $99.4(0.78)$ & $99.6(0.78)$ \\
$\mathrm{E}_{\mathrm{t}} \mathrm{CO}_{2}(\mathrm{mmHg})$ & $35.1(3.8)$ & $35.7(6.8)$ & $33.9(4.5)$ \\
$\mathrm{E}_{\mathrm{t}}$ Sevoflurane (\%) & $3.31(0.6)$ & $3.03(0.8)$ & $2.80(0.9)^{*}$ \\
\hline
\end{tabular}

Legend: $\mathrm{PIP}$ = peak inspired pressure; $\mathrm{C}_{\text {dyn }}=$ dynamic compliance expressed as $\mathrm{ml} / \mathrm{cm} \mathrm{H}_{2} \mathrm{O} / \mathrm{kg} ; \mathrm{V}_{\mathrm{T}}=$ tidal volume; MABP = mean arterial blood pressure; $\mathrm{S}_{\mathrm{p}} \mathrm{O}_{2}$ $=$ arterial oxygen saturation; $\mathrm{E}_{\mathrm{t}} \mathrm{CO}_{2}=$ end-tidal expired carbon dioxide; $\mathrm{E}_{\mathrm{t}}$ Sevoflurane = end-tidal expired sevoflurane (SD); ${ }^{*} \mathrm{p}<0.01$ compared to baseline; ${ }^{*} \mathrm{p}$ $<0.01$ compared to after cast. 
tracheal intubation. The time of cast restriction is short and compliance increases and PIP decreases after cast window cutouts are performed. If the anesthesiologist becomes concerned about the high PIP, tidal volume can be reduced or pressure control ventilation can be employed. These alternative forms of ventilation, however, would reduce tidal volume and may impair alveolar gas exchange.

There were statistically significant changes in heart rate and blood pressure. Mean arterial blood pressure increased when the cast was restrictive and heart rate decreased after cast cutout. These changes, however, were not clinically significant. We attempted to maintain a constant depth of anesthesia during all respiratory and cardiovascular measurements.

Shortcomings of the study include an unanticipated 19 per cent decrease in tidal volume $(8.8 \mathrm{ml} / \mathrm{kg}$ at baseline, $7.1 \mathrm{ml} / \mathrm{kg}$ after cast application). The reasons for this decrease were not obvious, but could be secondary to increased compressible volume in the breathing circuit. It is unlikely that a decrease in tidal volume of this magnitude would adversely affect the measurement of dynamic compliance. The change in compliance between the patients that had a change in tidal volume and those that did not was, in fact, not statistically different. Although we attempted to maintain a constant level of anesthesia, there was a statistically significant decrease in end-tidal sevoflurane concentration between the time of cast application and cast cutout. This decrease was of no clinical significance and was unlikely to influence cardiorespiratory function.

Our patients will be followed for months and years. Serial respiratory function measurements will be obtained during the casting treatment period. It will be of importance to know if pulmonary function improves after successive cast applications and how many patients may delay or avoid surgery in the future. Irrespective of the treatment method, serial measurements of respiratory function should be made to determine the effects of the treatment. Preservation and/or improvement in pulmonary function are also goals of scoliosis treatment, in addition to spine deformity correction [23-26].

Cast therapy for early onset scoliosis may become more common if its outcomes are better and unacceptable complications less than surgical techniques. The anesthesiologist must be aware of the transient changes in respiratory mechanics during application of the derotational thoracolumbar cast.

\section{Conclusion}

Derotational casting for children with early onset scoliosis produces a significant decrease in respiratory system compliance. The magnitude of the decrease mandates tracheal intubation for the procedure. Cast cut-out, how- ever, alleviates the severity of the changes in ventilation and tracheal extubation can be performed at the conclusion of the procedure.

\section{REFERENCES}

[1] T. Tsiligiannis and T. Grivas, "Pulmonary Function in Children with Idiopathic Scoliosis," Scoliosis, Vol. 7, 2012, pp. 7-12. http://dx.doi.org/10.1186/1748-7161-7-7

[2] J. Donath and A. Miller, "Restrictive Chest Wall Disorders," Seminars in Respiratory and Critical Care Medicine, Vol. 30, No. 3, 2009, pp. 275-292. http://dx.doi.org/10.1055/s-0029-1222441

[3] P. Fernandes and S. L. Weinstein, "Natural History of Early Onset Scoliosis," The Journal of Bone \& Joint Surgery, Vol. 89, Suppl. 1, 2007, pp. 21-33. http://dx.doi.org/10.2106/JBJS.F.00754

[4] L. A. Karol, "Early Definitive Spinal Fusion in Young Children," Clinical Orthopaedics and Related Research, Vol. 469, No. 5, 2011, pp. 1323-1329. http://dx.doi.org/10.1007/s11999-010-1622-z

[5] A. C. Koumbourlis, "Scoliosis and the Respiratory System,” Paediatric Respiratory Reviews, Vol. 7, No. 2, 2006, pp. 152-160.

http://dx.doi.org/10.1016/j.prrv.2006.04.009

[6] R. D. Labrom, "Growth and Maturation of the Spine from Birth to Adolescence,” The Journal of Bone \& Joint Surgery, Vol. 89, Suppl. 1, 2007, pp. 3-7.

[7] M. T. Hresko, "Idiopathic Scoliosis in Adolescents," The New England Journal of Medicine, Vol. 368, No. 9, 2013, pp. 834-841. http://dx.doi.org/10.1056/NEJMcp1209063

[8] K. Pehrsson, S. Larsson, A. Oden and A. Nachemson, "Long-Term Follow-Up of Patients with Untreated Scoliosis,” Spine, Vol. 17, No. 9, 1992, pp. 1091-1096. http://dx.doi.org/10.1097/00007632-199209000-00014

[9] S. M. Swank, R. B. Winter and J. H. Moe, "Scoliosis and Cor Pulmonale,” Spine, Vol. 7, 1982, pp. 343-354. http://dx.doi.org/10.1097/00007632-198207000-00004

[10] M. G. Vitale, J. A. Gomez, H. Matsumoto and D. P. Roye, "Variability of Expert Opinion in Treatment of EarlyOnset Scoliosis," Clinical Orthopaedics and Related Research, Vol. 469, No. 5, 2011, pp. 1317-1322. http://dx.doi.org/10.1007/s11999-010-1540-0

[11] J. M. Flynn, H. Matsumoto, F. Torres, N. Ramirez and M. G. Vitale, "Psychologic Dysfunction in Children Who Require Repetitive Surgery for Early Onset Scoliosis," Journal of Pediatric Orthopaedics, Vol. 32, No. 6, 2012, pp. 594-599. http://dx.doi.org/10.1097/BPO.0b013e31826028ea

[12] G. J. Redding and O. Mayer, "Structure-Respiration Function Relationships before and after Surgical Treatment of Early-Onset Scoliosis," Clinical Orthopaedics and Related Research, Vol. 469, No. 5, 2011, pp. 13301334. http://dx.doi.org/10.1007/s11999-010-1621-0

[13] M. H. Mehta, "Growth as a Corrective Force in the Early Treatment of Progressive Infantile Scoliosis," The Journal of Bone \& Joint Surgery, Vol. 87, No. 9, 2005, pp. 
1237-1247.

http://dx.doi.org/10.1302/0301-620X.87B9.16124

[14] J. O. Sanders, J. D’Astous, M. Fitzgerald, J. G. Khoury, S. Kishan and P. F. Sturm, "Derotational Casting for Progressive Infantile Scoliosis,” Journal of Pediatric Orthopaedics, Vol. 29, No. 6, 2009, pp. 581-587. http://dx.doi.org/10.1097/BPO.0b013e3181b2f8df

[15] A. A. Dhawale, S. A. Shah, S. Reichard, L. Holmes, R. Brislin, K. Rogers and W. G. Mackenzie, "Casting for Infantile Scoliosis: The Pitfall of Increased Peak Inspiratory Pressure,” Journal of Pediatric Orthopaedics, Vol. 33, No. 1, 2013, pp. 63-67. http://dx.doi.org/10.1097/BPO.0b013e318264936f

[16] A. Wald, D. Jason, T. W. Murphy and V. D. Mazzia, “A Computer System for Respiratory Parameters,” Computers and Biomedical Research, Vol. 2, No. 5, 1969, pp. 411-429.

[17] R. R. Uhl and F. J. Lewis, "Digital Computer Calculation of Human Pulmonary Mechanics Using a Least Squares Fit Technique," Computers and Biomedical Research, Vol. 7, No. 5, 1974, pp. 489-495.

[18] C. A. Stahl, K. Moller, S. Schumann, R. Kuhlen, M. Sydow, C. Putensen and J. Guttman, "Dynamic versus Static Respiratory Mechanics in Acute Lung Injury and Acute Respiratory Distress Syndrome,” Critical Care Medicine, Vol. 34, No. 8, 2006, pp. 2090-2098.

[19] A. Larsson, C. Jonmarker, S. G. E. Lindahl and O. Werner, "Lung Function in the Supine and Lateral Decubitus Positions in Anaesthetized Infants and Children," British Journal of Anaesthesia, Vol. 62, No. 4, 1989, pp. 378384.

[20] M. Yazici and J. Emans, "Fusionless Instrumentation
Systems for Congenital Scoliosis,” Spine, Vol. 34, 2009, pp. 1800-1807.

[21] J. E. Tis, L. I. Karlin, B. A. Akbarnia, L. C. Blakemore, G. H. Thompson, R. E. McCarthy, C. A. Tello, M. J. Mendelow and E. P. Southern, "Early Onset Scoliosis: Modern Treatment and Results," Journal of Pediatric Orthopaedics, Vol. 32, No. 7, 2012, pp. 647-657.

[22] L. A. Karol, C. Johnston, K. Mladenov, P. Schochet, P. Walters and R. H. Browne, "Pulmpnary Function Following Early Thoracic Fusion in Non-Neuromuscular Scoliosis,” The Journal of Bone \& Joint Surgery, Vol. 90, No. 6, 2008, pp. 1272-1281.

[23] D. M. Baulesh, J. Huh, T. Judkins, S. Garg, N. H. Miller and M. A. Erickson, "The Role of Serial Casting in EarlyOnset Scoliosis (EOS)," Journal of Pediatric Orthopaedics, Vol. 32, No. 7, 2012, pp. 658-663.

[24] N. D. Fletcher, A. McClung, K. E. Rathjen, J. R. Denning, R. Browne and C. E. Johnston, "Serial Casting as a Delay Tactic in the Treatment of Moderate-to-Severe EarlyOnset Scoliosis,” Journal of Pediatric Orthopaedics, Vol. 32, No. 7, 2012, pp. 664-671.

[25] E. K. Motoyama, V. F. Deeney, G. F. Fine, C. I. Yang, R. L. Mutich, S. A. Walczak and M. S. Moreland, "Effects on Lung Function of Multiple Expansion Thoracoplasty in Children with Thoracic Insufficiency Syndrome: A Longitudinal Study,” Spine, Vol. 31, 2006, pp. 284-290.

[26] E. K. Motoyama, C. I. Yang and V. F. Deeney, “Thoracic Malformation with Early-Onset Scoliosis: Effect of Serial VEPTR Expansion Thoracoplasty on Lung Growth and Function in Children," Paediatric Respiratory Reviews, Vol. 10, No. 1, 2009, pp. 12-17. 